\title{
Application of phage display technology to endothelial cell immunobiology
}

\author{
Andrew J.T. George \\ Dept of Immunology, Division of Medicine, Imperial \\ College School of Medicine, Hammersmith Hospital, \\ Du Cane Road, London, W12 ONN, UK
}

Endothelial cells are central to a wide range of inflammatory and normal immunological processes. This is in large part because the endothelium is responsible for the recruitment of leukocytes out of the circulation and into tissue. This occurs either as part of the normal circulation of these cells (for example into lymph nodes) or as part of an inflammatory process. As a result the control of endothelial function offers the potential for modulating a wide range of diseases. In addition, as the endothelial cells are often the first cells seen during an inflammatory reaction, they act as an early target of the immune response.

We have used phage display technology in a variety of ways to investigate or modulate endothelial function. In the first instance we have used an in vivo phage display approach to isolate novel antibodies against endothelial antigens. We have been probing the vascular endothelial cells associated with thymic tissue, with a view to dissecting out mechanisms responsible for the recruitment of thymoctyes to that organ. Injection of phage display libraries into animals, followed by isolation of phage from the thymus, has allowed the selection of $\mathrm{sFv}$ specific for thymus. Preliminary data concerning the characterisation of these $\mathrm{sFv}$ will be presented.

In xenotransplantation the endothelium is an important target of the rejection process, both the hyperacute antibody mediated rejection and cellular responses. We have used intracellular $\mathrm{sFv}$ to block the expression of two molecules involved in these processes. In the first we generated $\mathrm{sFv}$ against galactosyl transferase, the enzyme responsible for making the $\operatorname{Gal} \alpha(1-3)$ gal epitope recognised by natural antibodies. This was expressed in porcine endothelial cells as a fusion with the KDEL endoplasmic retention signal sequence. Expression of the carbohydrate was greatly reduced, and the cells became resistant to lysis with human natural antibodies.

A similar approach was also used to block VCAM-1 expression on the cell surface. This adhesion molecule is involved in recruitment of inflammatory leukocytes to the organ. Expression of an intracellular antibody reduced VCAM-1 expression by $>90 \%$ and effectively abolished VCAM dependent adherence.

Finally, we have used surface tethered sFv to modulate $\mathrm{T}$ cell responses. We have generated $\mathrm{sFv}$ specific for CD152 (CTLA4). This molecule downregulates T cell activation. We have generated constructs that result in expression of the sFv on the cell surface. These have been shown to block a mixed lymphocyte response.

In summary, phage derived $\mathrm{sFv}$ can be useful tools to probe the function of endothelial cells, as well as in modulating that function to reduce inflammatory responses, as seen in allograft rejection. 


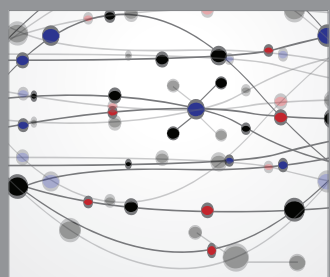

The Scientific World Journal
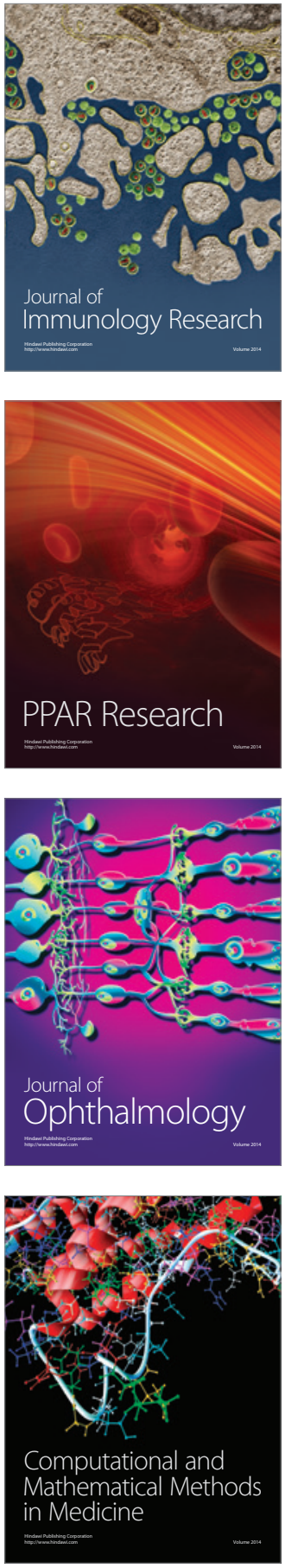

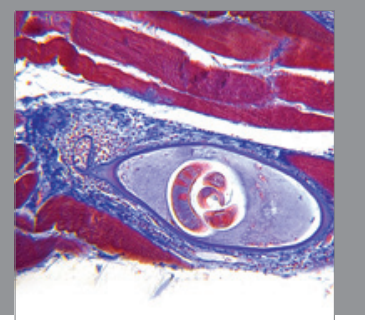

Gastroenterology

Research and Practice
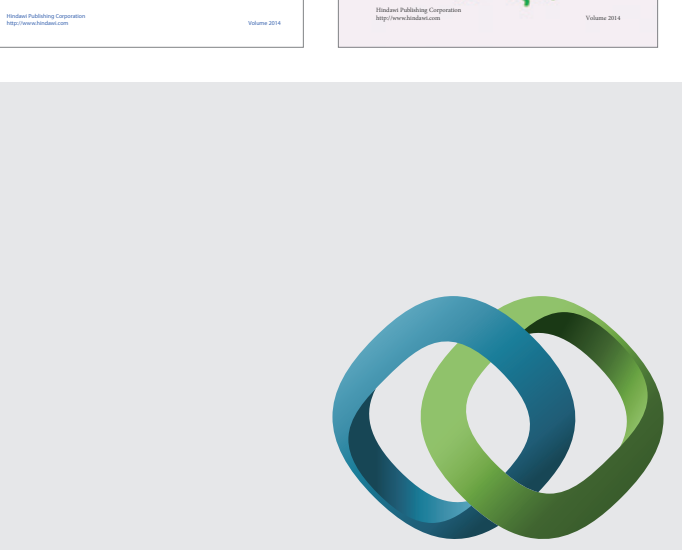

\section{Hindawi}

Submit your manuscripts at

http://www.hindawi.com
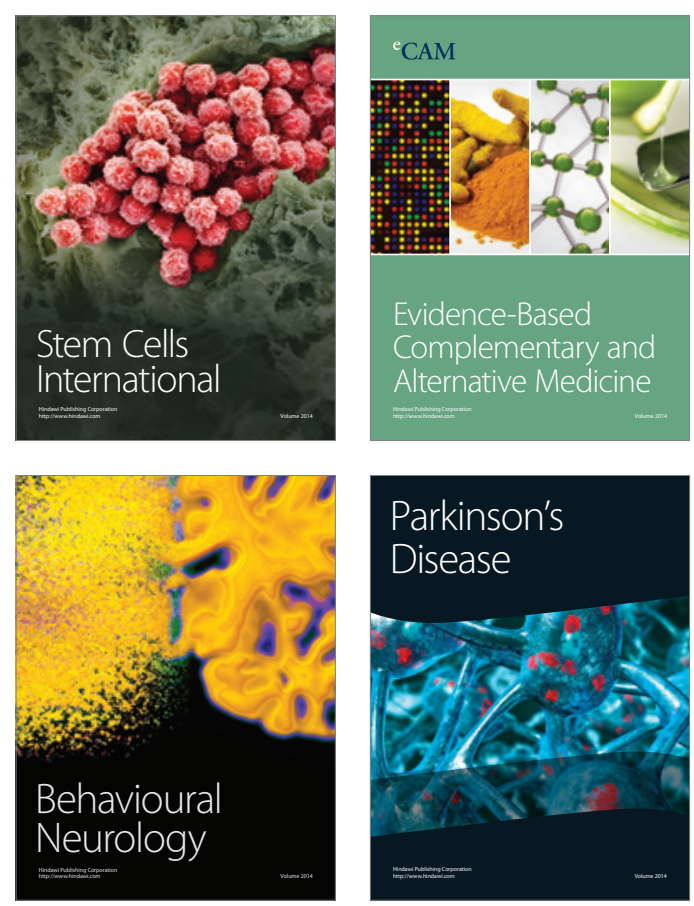

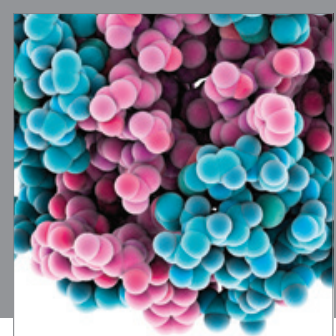

Journal of
Diabetes Research

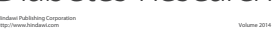

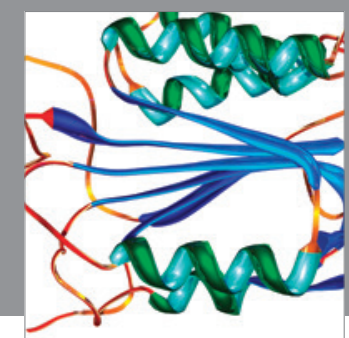

Disease Markers
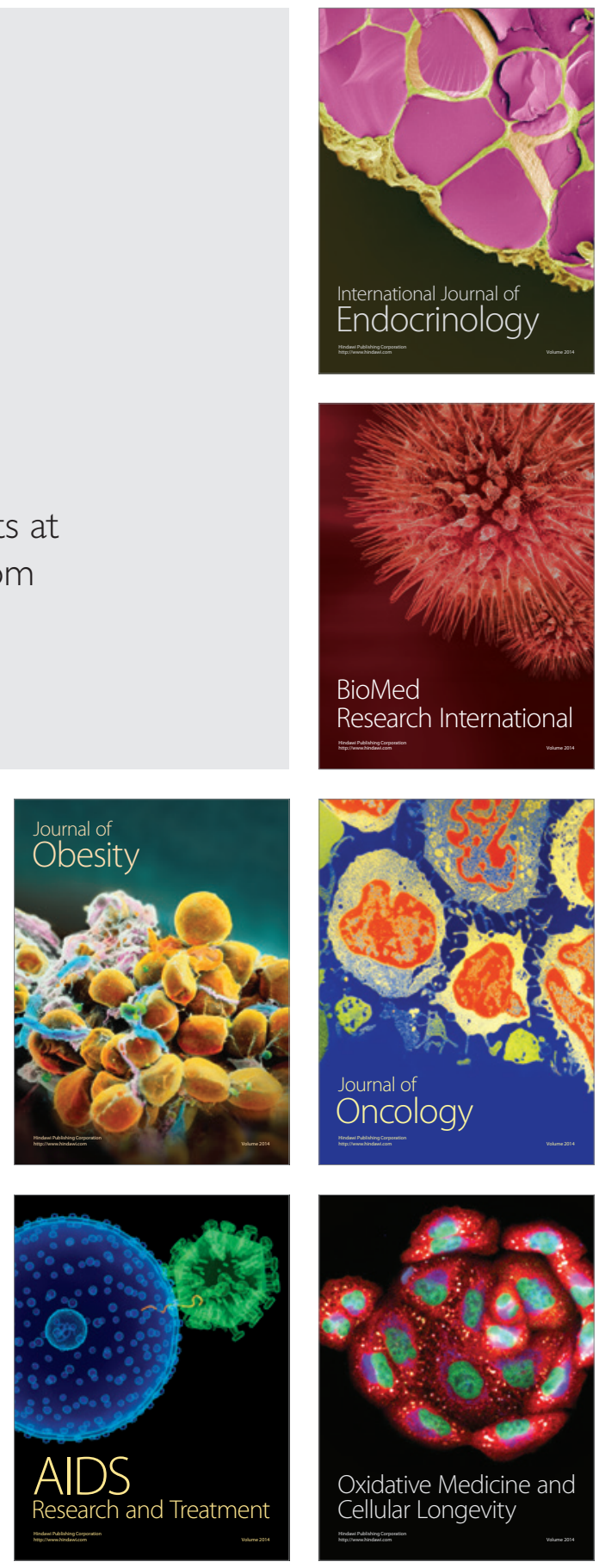